\title{
Molecular characteristics of screen-detected vs symptomatic breast cancers and their impact on survival
}

\author{
SJ Dawson 1,2,3,4, SW Duffy ${ }^{5}$, FM Blows', KE Driver', E Provenzano ${ }^{2,3,4}$, J LeQuesne ${ }^{1,2,3,4}$, DC Greenberg ${ }^{6}$, \\ P Pharoah ${ }^{1,3,4}$, C Caldas ${ }^{1,2,3,4}$ and GC Wishart ${ }^{*, 3,4}$
}

'Department of Oncology, Strangeways Research Laboratories, University of Cambridge, Cambridge CBI 8RN, UK; ${ }^{2}$ Cancer Research UK, Cambridge Research Institute, Li Ka Shing Centre, Robinson Way, Cambridge CB2 ORE, UK; ${ }^{3}$ Cambridge Breast Unit, Addenbrooke's Hospital, Cambridge University Hospital NHS Foundation Trust, Cambridge CB2 2QQ UK: ${ }^{4}$ Cambridge Biomedical Research Centre, National Institute of Health Research, Cambridge CB2 2QQ, UK: ${ }^{5}$ Cancer Research UK Centre for Epidemiology, Mathematics and Statistics, Wolfson Institute of Preventive Medicine, Barts and the London School of Medicine and Dentistry, Charterhouse Square, London ECI M 6BQ, UK; ${ }^{6}$ Eastern Cancer Registration and Information Centre, Unit C, Magog Court, Shelford Bottom, Hinton Way, Cambridge CB22 3AD, UK

BACKGROUND: Several recent studies have shown that screen detection remains an independent prognostic factor after adjusting for disease stage at presentation. This study compares the molecular characteristics of screen-detected with symptomatic breast cancers to identify if differences in tumour biology may explain some of the survival benefit conferred by screen detection.

METHODS: A total of I 379 women (aged 50-70 years) with invasive breast cancer from a large population-based case-control study were included in the analysis. Individual patient data included tumour size, grade, lymph node status, adjuvant therapy, mammographic screening status and mortality. Immunohistochemistry was performed on tumour samples using II primary antibodies to define five molecular subtypes. The effect of screen detection compared with symptomatic diagnosis on survival was estimated after adjustment for grade, nodal status, Nottingham Prognostic Index (NPI) and the molecular markers.

RESULTS: Fifty-six per cent of the survival benefit associated with screen-detected breast cancer was accounted for by a shift in the NPI, a further 3-10\% was explained by the biological variables and more than $30 \%$ of the effect remained unexplained.

CONCLUSION: Currently known biomarkers remain limited in their ability to explain the heterogeneity of breast cancer fully. A more complete understanding of the biological profile of breast tumours will be necessary to assess the true impact of tumour biology on the improvement in survival seen with screen detection.

British Journal of Cancer (2009) I 0 I, I338-1344. doi: I0.1038/sj.bjc.6605317 www.bjcancer.com

Published online 22 September 2009

(c) 2009 Cancer Research UK

Keywords: breast cancer; breast screening; survival; immunohistochemistry; biomarkers

Breast cancer is the most common female cancer in the UK with more than 45000 women diagnosed per annum. The National Health Service Breast Screening Programme (NHSBSP) was introduced in 1988 in the UK and around 15000 breast cancer cases are now detected every year through screening. The NHSBSP initially offered three yearly mammography to women aged 50-65 years, however, since 2004 the upper age limit has been increased to 70 years, with approximately two million women now screened in the UK each year.

The widespread introduction of mammographic screening for breast cancer has led to a significant reduction in breast cancer mortality. The policy of offering screening is associated with a $20 \%$ reduction in breast cancer mortality and the effect of actually attending screening is likely to be considerably larger (Vainio, 2002). Although women with screen-detected breast cancers have an improved prognosis compared with those diagnosed with

\footnotetext{
*Correspondence: Professor GC Wishart, Cambridge Breast Unit, Cambridge University Hospitals NHS Foundation Trust, Hills Road, Cambridge CB2 2QQ, UK; E-mail: gordon.wishart@addenbrookes.nhs.uk Received 9 July 2009; accepted 19 August 2009; published online 22 September 2009
}

tumours outside of screening (i.e. symptomatic tumours), there are multiple biases that may contribute to this difference. These include lead-time bias (cancers detected by screening are identified earlier in their natural history) and length bias (cancers with a favourable natural history are more likely to be detected by screening as they remain asymptomatic for longer; Shapiro et al, 1974; Zahl et al, 2004).

Screen-detected cancers are more likely to be smaller in size and well differentiated, and are less likely to be associated with regional lymph node involvement (Porter et al, 1999; Weaver et al, 2006). Until recently, the survival benefit conferred from screen detection has largely been attributed to this stage shift. However, several recent studies have shown that screen detection remains an independent prognostic factor after adjusting for disease stage (Joensuu et al, 2004; Shen et al, 2005; Wishart et al, 2008). In the largest UK series, which was performed by our group, only $72 \%$ of the survival benefit associated with screen-detected breast cancers was accounted for by age and shift in the Nottingham Prognostic Index (NPI), a prognostic tool based on tumour size, grade and lymph node status (Wishart et al, 2008). These results confirm that lead-time bias alone cannot fully explain the improved prognosis associated with screening. The remaining survival 
benefit conferred from screen-detection has not been fully explained, but may relate to differences in tumour biology between screen-detected and symptomatic cancers.

In recent years, microarray-based technology has resulted in the identification of clinically relevant molecular subtypes of breast cancer, providing insights into the molecular heterogeneity of the disease (Perou et al, 2000; Sorlie et al, 2003). Five distinct breast cancer subtypes have been identified based on gene expression signatures: luminal A, luminal B, HER2 overexpressing, basal-like and normal breast tissue-like. The differences in gene expression patterns among the subtypes reflect basic alterations in the cell biology of the tumours and have been associated with significant variation in clinical outcome. Luminal A tumours have been associated with the best prognosis whereas basal-like and HER2overexpressing tumours show shorter disease-free intervals and worse overall survival (Sorlie et al, 2003).

Protein expression profiling using immunohistochemistry has been used to describe a similar molecular taxonomy of the disease (Callagy et al, 2003; Abd El-Rehim et al, 2005; Jacquemier et al, 2005). Luminal A and luminal B breast cancers express the oestrogen receptor (ER) and are also frequently progesterone receptor (PR) positive. HER2 expression is associated with the HER2-overexpressing and luminal B subtypes. Basal-like cancers are characteristically negative for ER, PR and HER2 expression (i.e. triple negative) but may express basal cytokeratins (CK5-6 and CK14) and the epidermal growth factor receptor (EGFR) (Nielsen et al, 2004; Rakha et al, 2006). In this context, immunohistochemistry can be used to identify distinct molecular subtypes of breast cancer, contributing to our understanding of the biological diversity of the disease.

It is currently not known whether variation in the molecular characteristics of screen-detected $v s$ symptomatic breast cancers contributes to the differences seen in prognosis between these two groups. The aims of the present study were to examine the molecular characteristics of screen-detected $v s$ symptomatic breast cancers and to identify if differences in tumour biology may explain some of the survival benefit conferred by screen detection.

\section{MATERIALS AND METHODS}

\section{Study population}

A total of 1379 women diagnosed with invasive breast cancer were included in this analysis from their participation in a large population-based case-control study; the Study of Epidemiology and Risk Factors in Cancer Heredity (SEARCH). Cases for SEARCH are identified through the Eastern Cancer Registration and Information Centre and details of the study have been published previously (Lesueur et al, 2005). The criteria for inclusion of cases in the current analysis were those aged between 50 and 70 years at diagnosis (the age range of the NHSBSP) with available tumour samples, pathology data (tumour size, tumour grade, lymph node status) and individual outcome data (vital status at last follow-up and date of death). The NPI was calculated for each case using tumour size, lymph node status and histological grade, and cases were classified into five different prognostic groups based on the NPI; excellent $(\mathrm{NPI}<2.4)$, good $(2.4<\mathrm{NPI}<3.4)$, moderate $1(3.4<\mathrm{NPI}<4.4)$, moderate 2 $(4.4<\mathrm{NPI}<5.4)$ and poor (NPI $\geqslant 5.4)$ (Sundquist et al, 1999).

\section{Tumour samples and immunostaining}

Tissue microarrays were constructed using a tissue microarrayer (Beecher Instruments, Sun Prairie, WI, USA) as previously described with a single representative $0.6 \mathrm{~mm}$ tissue core taken from each tumour block (Kononen et al, 1998). Sections from the tissue microarrays were cut at $3 \mu \mathrm{m}$ for subsequent immunostaining. Immunostaining using the BOND-maX automated immu- nostainer (Leica Microsystems, Bucks, UK) was performed for the following 11 primary antibodies: ER, PR, HER2, CK 5-6, CK14, EGFR, E-cadherin, Ki-67, BCL2, p63 and $\alpha$-smooth muscle actin (ASMA). Details of the primary antibodies and antigen retrieval methods are given in Supplementary Table 1. Tumours and tissues with known staining patterns were used as positive immunostaining controls and normal tissues were used a negative controls.

Following antibody staining, the slides were scanned into the Ariol high-throughput image analysis system (Applied Imaging Corp, San Diego, CA, USA). All immunohistochemistry was scored by SJD. Details of the scoring methods used and the cut-off values applied to each marker to indicate positive and negative staining are shown in Supplementary Table 1. Cores containing no evidence of tumour or carcinoma in situ were excluded from the analysis. Nuclear staining for ER and PR was recorded using the Allred scoring system; a simple additive scoring system of an intensity and proportion value that gives a range from 0 to 8 (intensity score range $0-3$; proportion score range $0-5(0=$ no staining; $1 \leqslant 1 \%$; $2=1-10 \% ; 3=11-33 \% ; 4=34-66 \% ; 5=67-100 \%))$. A total score of $>2$ was defined as positive (Leake et al, 2000). HER2 was scored using the HercepTest; score $0=$ no staining or staining in $\leqslant 10 \%$ cells, $1=$ weak incomplete membrane staining in $>10 \%$ of cells, $2=$ moderate complete membrane staining in $>10 \%$ cells, $3=$ strong complete uniform membranous staining in $>10 \%$ of cells. A score of 2 or 3 was considered positive (Carlson et al, 2006). Scoring methods and cut-off values for the other immunohistochemical markers were defined from previous studies (Callagy et al, 2003, 2006; Rakha et al, 2006, 2007).

\section{Molecular subtype classification}

Tumours were classified into five molecular groups based on the expression of ER, PR, HER2, basal cytokeratins and EGFR as follows: subtype 1 (luminal A) $=\mathrm{ER}+$ and/or PR + and HER2-; subtype 2 (luminal $\mathrm{B})=\mathrm{ER}+$ and/or $\mathrm{PR}+$ and HER2 + ; subtype 3 (HER2 over-expressing) $=\mathrm{ER}-$ and PR - and HER $2+$; subtype 4 (triple negative without expression of core basal markers) $=\mathrm{ER}-$, PR -, HER2 - and CK5/6-, CK14-, EGFR-; subtype 5 (triple negative with expression of core basal markers) $=$ ER - , PR-, HER2and CK5/6 + and/or CK14+ and/or EGFR +.

\section{Statistical analysis}

Differences between screen-detected and symptomatic patients regarding categorical variables were assessed using the $\chi^{2}$-test. Cox regression analysis was used to determine the effect of each factor on all-cause mortality after diagnosis. Follow-up was censored on the date of death from any cause, or, if death did not occur, on the date last known alive or at 15 years after diagnosis, whichever came first. Time at risk began on the date of entry into SEARCH to allow for the fact that SEARCH is an ongoing epidemiology study and some cases are recruited after diagnosis (Azzato et al, 2009). The effect of screen detection as compared with symptomatic diagnosis on survival was first estimated unadjusted and then adjusted for NPI and individual marker expression. The percentage of the effect of screen detection accounted for by other factors was estimated using the measure mentioned by Freedman et al (1992). This is defined as

$$
P=100\left\{1-\frac{a}{b}\right\}
$$

where $b$ is the unadjusted logarithm of the hazard ratio and $a$ the adjusted. Thus, for example, if after adjustment there is no effect, $a=0$, and the Freedman statistic will be $100 \%$. If the adjustment makes no difference whatever, $a=b$, and the Freedman statistic is $0 \%$. All analyses were performed using SPSS statistical software version 16.0, or Intercooled Stata version 9.0 (StataCorp, College Station, TX, USA). 
Table I Case and tumour characteristics

\begin{tabular}{|c|c|c|c|}
\hline \multirow[b]{2}{*}{ Characteristic } & \multicolumn{2}{|c|}{$\begin{array}{c}\text { Mode of breast cancer } \\
\text { detection }\end{array}$} & \multirow[b]{2}{*}{ P-value } \\
\hline & $\begin{array}{l}\text { Screen } \\
\text { detected } \\
(n=610)\end{array}$ & $\begin{array}{c}\text { Not screen } \\
\text { detected } \\
(n=769)\end{array}$ & \\
\hline \multicolumn{4}{|l|}{ Age at diagnosis (years) } \\
\hline $50-59$ & $37 \mid(61)$ & $520(68)$ & 0.009 \\
\hline $60-70$ & $239(39)$ & $249(32)$ & \\
\hline Mean follow-up (years, range) & $6.9(1.3-15.6)$ & $7.1(0.7-16)$ & 0.06 \\
\hline Deaths, $n(\%)$ & $52(9)$ & $153(20)$ & $<0.000$ \\
\hline \multicolumn{4}{|l|}{ Tumour size, n (\%) } \\
\hline $2 \mathrm{~cm}$ & $482(85)$ & $429(59)$ & $<0.0001$ \\
\hline$>2-5 \mathrm{~cm}$ & $84(14)$ & $284(39)$ & \\
\hline$>5 \mathrm{~cm}$ & $4(1)$ & $19(2)$ & \\
\hline \multicolumn{4}{|l|}{ Grade, n (\%) } \\
\hline I & $|8|(34)$ & $153(23)$ & $<0.0001$ \\
\hline 2 & $277(51)$ & $296(45)$ & \\
\hline 3 & $82(15)$ & $213(32)$ & \\
\hline \multicolumn{4}{|l|}{ Nodal status, n (\%) } \\
\hline Negative & $400(75)$ & $426(60)$ & $<0.0001$ \\
\hline Positive & $134(25)$ & $290(40)$ & \\
\hline \multicolumn{4}{|l|}{ NPI group, n (\%) } \\
\hline Excellent & $101(25)$ & $57(10)$ & $<0.0001$ \\
\hline Good & $132(33)$ & $112(21)$ & \\
\hline Moderate I & $100(25)$ & $123(23)$ & \\
\hline Moderate 2 & $46(\mid 1)$ & $147(27)$ & \\
\hline Poor & $25(6)$ & $106(19)$ & \\
\hline \multicolumn{4}{|l|}{ Morphology, n (\%) } \\
\hline Ductal & $454(74)$ & $547(7 \mathrm{I})$ & 0.05 \\
\hline Lobular & $102(17)$ & $159(21)$ & \\
\hline Other & $54(9)$ & $61(8)$ & \\
\hline \multicolumn{4}{|l|}{ Chemotherapy, n (\%) } \\
\hline Yes & $83(17)$ & $204(30)$ & $<0.0001$ \\
\hline No & $406(83)$ & $474(70)$ & \\
\hline \multicolumn{4}{|l|}{ Hormonal therapy, n (\%) } \\
\hline Yes & $543(89)$ & $656(85)$ & 0.10 \\
\hline No & $67(11)$ & $112(15)$ & \\
\hline
\end{tabular}

Abbreviation: $\mathrm{NPI}=$ Nottingham Prognostic Index.

\section{RESULTS}

\section{Characteristics of breast cancers and mode of detection}

Baseline clinical and pathology data from the 1379 women included in the analysis are summarised in Table 1. Of these women, 610 (44\%) had screen-detected tumours and 769 (56\%) had symptomatic tumours detected without screening. Mean follow-up of the study population was 7 years (range 0.7-16 years). Breast cancers identified through screening were smaller than those found without screening (85 vs 59\% respectively had tumour size $\leqslant 2 \mathrm{~cm}$, $P<0.0001)$. Screen-detected tumours were more likely to have lower histological grade (34 vs $23 \%$ were grade $1, P<0.0001$ ) and less likely to have lymph node involvement ( 25 vs $40 \%, P<0.0001)$. In keeping with these findings, screen-detected tumours were more likely to have favourable NPI categories $(P<0.0001)$. Women with screen-detected tumours were also less likely to receive adjuvant systemic chemotherapy (17 vs 30\%, $P<0.0001$ ).

A higher proportion of tumours detected at screening were $\mathrm{ER}+(86$ vs $74 \%, P<0.0001))$ and $\mathrm{PR}+(74$ vs $65 \%, P=0.002)$
Table 2 Molecular characteristics

\begin{tabular}{|c|c|c|c|}
\hline \multirow[b]{2}{*}{ Characteristic } & \multicolumn{2}{|c|}{ Mode of breast cancer detection } & \multirow[b]{2}{*}{$P$-value } \\
\hline & $\begin{array}{l}\text { Screen } \\
\text { detected } \\
(n=610)\end{array}$ & $\begin{array}{c}\text { Not screen } \\
\text { detected } \\
(n=769)\end{array}$ & \\
\hline \multicolumn{4}{|l|}{ ER status, $\mathrm{n}(\%)$} \\
\hline Positive & $352(86)$ & $410(74)$ & $<0.0001$ \\
\hline Negative & $56(14)$ & $144(26)$ & \\
\hline \multicolumn{4}{|l|}{ PR status, $\mathrm{n}(\%)$} \\
\hline Positive & $302(74)$ & $350(65)$ & 0.002 \\
\hline Negative & $106(26)$ & $|9|(35)$ & \\
\hline \multicolumn{4}{|l|}{ HER2 status, n (\%) } \\
\hline Positive & $34(8)$ & $63(12)$ & 0.10 \\
\hline Negative & 371 (92) & $478(88)$ & \\
\hline \multicolumn{4}{|l|}{ CK5-6 status, n (\%) } \\
\hline Positive & $44(11)$ & $52(10)$ & 0.65 \\
\hline Negative & $37 \mid(89)$ & $483(90)$ & \\
\hline \multicolumn{4}{|l|}{ CKI 4 status, n (\%) } \\
\hline Positive & $16(4)$ & $20(4)$ & 0.83 \\
\hline Negative & $392(96)$ & $528(96)$ & \\
\hline \multicolumn{4}{|l|}{ EGFR status, n (\%) } \\
\hline Positive & $25(6)$ & $60(11)$ & 0.012 \\
\hline Negative & $367(94)$ & 477 (89) & \\
\hline \multicolumn{4}{|c|}{ E-cadherin status, $\mathrm{n}(\%)$} \\
\hline Positive & $303(74)$ & $415(75)$ & 0.65 \\
\hline Negative & $107(26)$ & $137(25)$ & \\
\hline \multicolumn{4}{|l|}{ Ki-67 status, n (\%) } \\
\hline Positive & $26(6)$ & $86(15)$ & $<0.0001$ \\
\hline Negative & $382(94)$ & $473(85)$ & \\
\hline \multicolumn{4}{|l|}{ BCL2 status, $\mathrm{n}$ (\%) } \\
\hline Positive & $360(90)$ & $442(83)$ & 0.003 \\
\hline Negative & $42(10)$ & $93(17)$ & \\
\hline \multicolumn{4}{|l|}{ p63 status, n (\%) } \\
\hline Positive & $3(1)$ & $2(1)$ & 0.43 \\
\hline Negative & 403 (99) & $543(99)$ & \\
\hline \multicolumn{4}{|l|}{ ASMA status, n (\%) } \\
\hline Positive & $18(4)$ & $26(5)$ & 0.75 \\
\hline Negative & $390(96)$ & $510(95)$ & \\
\hline Subtype I, n (\%) ${ }^{\mathrm{a}}$ & $322(85)$ & $366(72)$ & $<0.000$ I \\
\hline Subtype 2, n (\%) & $21(5)$ & $32(6)$ & 0.62 \\
\hline Subtype $3, n(\%)$ & $12(3)$ & $24(5)$ & 0.216 \\
\hline Subtype 4, n (\%) & $7(2)$ & $28(6)$ & 0.005 \\
\hline Subtype $5, n(\%)$ & $19(5)$ & $56(11)$ & 0.001 \\
\hline
\end{tabular}

Abbreviations: $\mathrm{ASMA}=\alpha$-smooth muscle actin; $E G F R=$ epidermal growth factor receptor; $E R=$ oestrogen receptor; $\mathrm{NPI}=$ Nottingham Prognostic Index; $\mathrm{PR}=$ pro-

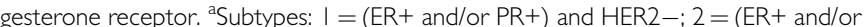
$\mathrm{PR}+)$ and HER2+; $3=(\mathrm{ER}-$ and PR- $)$ and HER2+; $4=($ ER - , PR-, HER2 -$)$ and $(\mathrm{CK} 5 / 6-, \mathrm{CKI} 4-$ and EGFR-); $5=($ ER-, PR-, HER2 -$)$ and $(\mathrm{CK} 5 / 6+$ and/or CKI4+ and/or EGFR+).

(Table 2). BCL2 was highly expressed in screen-detected tumours ( 90 vs $83 \%, P=0.003$ ) and lower rates of Ki-67 positivity (6 vs 15\%, $P<0.0001)$ were identified. There was no significant difference in the expression of the basal cytokeratins between the two groups but a higher proportion of tumours detected without screening expressed EGFR (6 vs 11\%, $P=0.012$ ).

\section{Molecular subtypes of breast cancer and mode of detection}

The distribution of the five defined molecular subtypes was explored in cancers detected at screening and those detected without screening (Table 2; Figure 1). Tumours detected at 

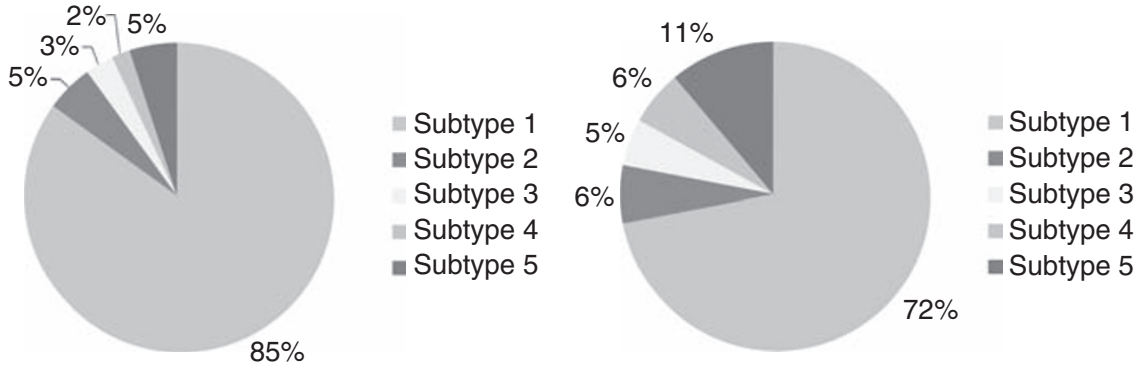

Figure I Breast cancer molecular subtypes by mode of breast cancer detection. Subtypes: $I=(E R+$ and/or PR +$)$ and $H E R 2-; 2=(E R+$ and/or $\mathrm{PR}+)$ and HER2 $+; 3=(\mathrm{ER}-$ and PR-) and HER2 $+; 4=(\mathrm{ER}-, \mathrm{PR}-, \mathrm{HER} 2-)$ and $(\mathrm{CK} 5 / 6-, \mathrm{CK} 14-$ and EGFR-); $5=(\mathrm{ER}-, \mathrm{PR}-, \mathrm{HER} 2-)$ and $(\mathrm{CK} 5 /$ $6+$ and/or $\mathrm{CKI} 4+$ and/or EGFR + ).

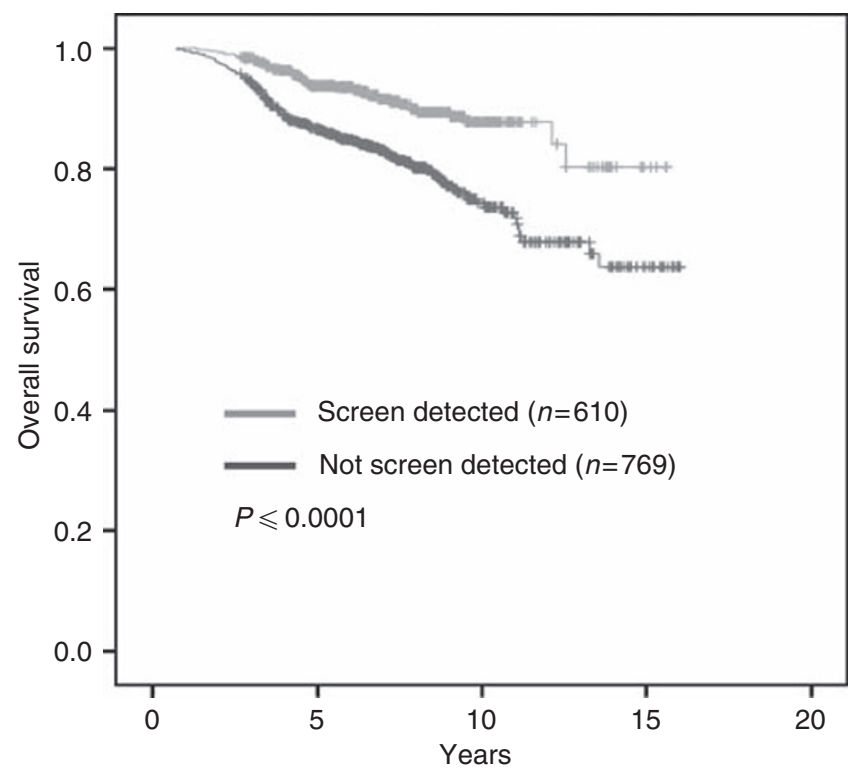

Figure 2 Overall survival by mode of breast cancer detection.

screening were more likely to belong to the luminal A subtype (subtype 1; 85 vs $72 \%, P<0.0001$ ). Furthermore, screen-detected tumours were less likely to belong to the basal-like subtype as defined by either the triple negative phenotype (subtype $4 ; 2$ vs $6 \%$, $P=0.005$ ) or the triple negative phenotype and the expression of core basal markers (subtype $5 ; 5$ vs $11 \%, P=0.001$ )). The prevalence of luminal B (7vs 5\%, $P=0.62)$ and HER2-overexpressing subtypes (5 vs $3 \%, P=0.22$ ) was similar between the screendetected and non-screen-detected groups.

\section{Overall survival by mode of detection and molecular subtype}

Univariate analysis Women with screen-detected tumours had improved overall survival compared to women with tumours detected without screening $(P<0.0001$; Figure 2$)$. Univariate analysis of mode of detection, age at diagnosis, tumour size, grade, nodal status and NPI group showed that all factors except age had highly significant effects on survival (Table 3 ).

When comparing survival according to molecular subtype, the luminal A subtype was associated with the best overall survival and the HER2-overexpressing subtype with the worst (Table 4). Tumours detected by screening generally had more favourable outcomes than non-screen-detected cancers regardless of the molecular subtype (Table 3 ). In the luminal A subtype (subtype 1),
Table 3 Univariate analysis of overall survival

\begin{tabular}{|c|c|c|}
\hline & Hazard ratio $(95 \% \mathrm{Cl})$ & $P$-value \\
\hline \multicolumn{3}{|c|}{ Mode of detection $(n=1379)$} \\
\hline Not screen detected & 1.00 & \\
\hline Screen detected & $0.43(0.31-0.59)$ & $<0.0001$ \\
\hline \multicolumn{3}{|l|}{ Age at diagnosis $(n=1400)$} \\
\hline $50-59$ & 1.00 & \\
\hline $60-70$ & $1.01(0.74-1.35)$ & 0.99 \\
\hline \multicolumn{3}{|l|}{ Tumour size $(n=1319)$} \\
\hline $2 \mathrm{~cm}$ & 1.00 & \\
\hline$>2-5 \mathrm{~cm}$ & $2.11(1.56-2.85)$ & $<0.0001$ \\
\hline$>5 \mathrm{~cm}$ & $5.88(3.23-10.73)$ & $<0.0001$ \\
\hline \multicolumn{3}{|l|}{ Grade $(n=1218)$} \\
\hline 1 & 1.00 & \\
\hline 2 & $1.98(1.21-3.23)$ & 0.006 \\
\hline 3 & $5.42(3.35-8.75)$ & $<0.000$ । \\
\hline \multicolumn{3}{|l|}{ Nodal status $(n=1267)$} \\
\hline Negative & 1.00 & \\
\hline Positive ( $1-3$ nodes) & $2.35(1.65-3.35)$ & $<0.0001$ \\
\hline Positive (4 nodes) & $8.18(5.75-11.65)$ & $<0.0001$ \\
\hline \multicolumn{3}{|l|}{ NPI group $(n=961)$} \\
\hline Excellent & 1.00 & \\
\hline Good & $3.22(1.10-9.47)$ & 0.034 \\
\hline Moderate I & $4.70(1.64-13.52)$ & 0.004 \\
\hline Moderate 2 & $7.36(2.61-20.77)$ & $<0.0001$ \\
\hline Poor & $27.77(|0.09-76.4|)$ & $<0.0001$ \\
\hline
\end{tabular}

Abbreviation: NPI = Nottingham Prognostic Index.

overall survival at 15 years was $94 \%$ among women with screendetected cancers compared to $84 \%$ in the non-screen-detected group $(P=0.001)$.

Multivariate analysis The effect of screen detection on survival was then explored in a multivariate analysis after adjustment for tumour characteristics, the NPI, individual molecular biomarker expression and molecular subtype (Table 5). The effect of screen detection on survival was significantly attenuated after adjustment for the NPI with the hazard ratio changing from 0.43 to 0.69 . Further adjustment of the model to incorporate expression of individual markers or the molecular subtype resulted in minimal change in the survival benefit conferred by screen detection.

The Freedman estimate of the proportion of the survival advantage from screen detection attributable to NPI was $56 \%$. As one might argue that histological grade, a component of the NPI, is a biological variable, we also estimated the proportion attributable 
Table 4 Overall survival by breast cancer molecular subtype

\begin{tabular}{lcccc}
\hline & & \multicolumn{2}{c}{ Overall survival (15 years) } & \\
\cline { 3 - 4 } $\begin{array}{l}\text { Molecular } \\
\text { subtype }\end{array}$ & $\boldsymbol{n}$ & $\begin{array}{c}\text { Screen } \\
\text { detected (\%) }\end{array}$ & $\begin{array}{c}\text { Not screen } \\
\text { detected (\%) }\end{array}$ & P-value \\
\hline Subtype 1 & 688 & 94 & 84 & 0.001 \\
Subtype 2 & 53 & 86 & 78 & 0.52 \\
Subtype 3 & 36 & 83 & 54 & 0.12 \\
Subtype 4 & 35 & 86 & 64 & 0.24 \\
Subtype 5 & 75 & 84 & 79 & 0.60 \\
\hline
\end{tabular}

a Subtypes: I $=($ ER+ and/or PR+ $)$ and HER2-; $2=($ ER+ and/or PR+ $)$ and HER2+; $3=($ ER - and PR- $)$ and HER2 $+; 4=($ ER - , PR-, HER2 -$)$ and $(C K 5 / 6-$, CKI4and EGFR-); $5=($ ER-, PR-, HER2 -$)$ and (CK5/6+ and/or CKI4+ and/or EGFR+).

to size and node status only. This was $53 \%$. Adjustment for the other molecular characteristics in addition to NPI gave attributable proportions ranging from 59 to $66 \%$. Multivariate adjustment for several biological variables did not substantially change the proportion of the screen detection effect explained. Thus, additional adjustment for molecular characteristics explained a further $3-10 \%$ of the survival advantage of screen-detected tumours in addition to NPI $(6-13 \%$ in addition to size and node status). Currently known biomarkers and tumour characteristics still remain limited in their ability to explain the heterogeneity of breast cancer fully. It is likely that a more complete understanding of the biological profile of breast tumours will be necessary to eliminate potential length bias and adjust for its impact on the improvement in survival seen with screen detection.

\section{DISCUSSION}

Women with screen-detected cancers have a strong survival advantage compared to women with symptomatic cancers detected without screening (Gotzsche and Nielsen, 2006). The majority of this survival benefit is explained by stage shift as tumours detected by screening are identified earlier in their natural history and consequently have an improved prognosis (Wishart et al, 2008). However, after adjustment for age and NPI, approximately onethird of the screen detection survival advantage has remained unexplained. It has been hypothesised that the remaining survival benefit conferred by screen detection may relate to differences in tumour biology between screen-detected and symptomatic cancers. We analysed the molecular characteristics of screen-detected $v s$ symptomatic breast cancers in 1379 women diagnosed with invasive breast cancer in the East of England to identify if differences in tumour biology may explain some of the survival benefit conferred by screen detection. Although differences in the molecular subtype of screen-detected $v s$ symptomatic cancers were identified, the expression of individual molecular biomarkers had minimal effect on the improved outcome associated with screen detection.

Favourable molecular characteristics have previously been described in screen-detected tumours including higher expression of ER and PR and less frequent expression of HER2 and Ki-67 (Crosier et al, 1999; Joensuu et al, 2004). Our current analysis confirmed these findings and identified that screen-detected tumours were more likely to be $\mathrm{ER}+, \mathrm{PR}+$ and $\mathrm{Ki}-67-$. In our study, a low frequency of HER $2+$ breast cancer was identified, which is not an unexpected finding given that the cohort was population based. The proportion of HER $2+$ cases was found to be similar between the screen-detected and symptomatic tumours. Our analysis also identified that a higher proportion of breast cancers diagnosed without screening were triple negative. Symptomatic tumours were more likely to be EGFR + although expression of the basal cytokeratins (CK5-6 and CK14) did not differ
Table 5 Attenuation of the effect of screen detection on survival after adjustment for different factors

\begin{tabular}{lccc}
\hline & $\begin{array}{c}\text { Hazard Ratio } \\
(\mathbf{9 5 \%} \text { Cl) }\end{array}$ & & \\
$\begin{array}{l}\text { Factors } \\
\text { adjusted for }\end{array}$ & $\begin{array}{c}\text { Screen detected vs not } \\
\text { screen detected }\end{array}$ & P-value & $\begin{array}{c}\text { Freedman } \\
\text { statistic (\%) }\end{array}$ \\
\hline None & $0.43(0.31-0.59)$ & $<0.0001$ & - \\
Grade & $0.50(0.35-0.71)$ & $<0.0001$ & 18 \\
Size & $0.52(0.37-0.74)$ & $<0.0001$ & 22 \\
Nodal status & $0.60(0.43-0.84)$ & 0.003 & 39 \\
Size and nodal status & $0.67(0.47-0.94)$ & 0.02 & 53 \\
NPI & $0.69(0.46-1.03)$ & 0.07 & 56 \\
NPI and ER & $0.71(0.45-1.14)$ & 0.16 & 59 \\
NPI and PR & $0.72(0.45-1.16)$ & 0.18 & 61 \\
NPI and HER2 & $0.72(0.45-1.15)$ & 0.16 & 61 \\
NPI and CK5-6 & $0.75(0.47-1.19)$ & 0.22 & 66 \\
NPI and CKI4 & $0.68(0.43-1.09)$ & 0.11 & 54 \\
NPI and EGRR & $0.63(0.38-1.03)$ & 0.07 & 45 \\
NPI and E-cadherin & $0.65(0.41-1.05)$ & 0.08 & 49 \\
NPI and Ki-67 & $0.72(0.45-1.14)$ & 0.08 & 61 \\
NPI and BCL2 & $0.71(0.44-1.15)$ & 0.16 & 59 \\
NPI and p63 & $0.59(0.36-0.94)$ & 0.03 & 37 \\
NPI and ASMA & $0.72(0.45-1.14)$ & 0.16 & 61 \\
NPI and molecular & $0.64(0.38-1.08)$ & 0.09 & 47 \\
subtype & & &
\end{tabular}

Abbreviations: $A S M A=\alpha$-smooth muscle actin; $E G F R=$ epidermal growth factor receptor; $\mathrm{ER}=$ oestrogen receptor; $\mathrm{NPI}=$ Nottingham Prognostic Index; PR $=$ progesterone receptor.

significantly between the screen-detected and symptomatic tumours. A previous small study of 95 interval cancers diagnosed in Norway has reported that cancers detected without screening were more likely to show a basal epithelial phenotype as defined by CK5-6 positivity (Collett et al, 2005). Finally, we identified that screen-detected tumours were more likely to show higher expression of BCL2, an anti-apoptotic protein whose expression is associated with improved survival from breast cancer (Callagy et al, 2006, 2008).

Despite the identification of distinct differences in the molecular characteristics of screen-detected $v s$ symptomatic breast cancers, our analysis showed minimal attenuation of the screen-detected survival advantage after adjustment for the expression of individual molecular biomarkers or molecular subtype in multivariate analysis. The Freedman estimates of the proportion of the effect suggest that the NPI explains $56 \%$ of the effect, up to a further $10 \%$ is explained by the biological variables and more than $30 \%$ of the effect remains unexplained. In a recent study by Shito et al (2008), cancer detection at screening independently predicted favourable distant disease-free survival when molecular subtype was included as a covariate in multivariate analysis in addition to age, grade and tumour size. The authors concluded that the differences in molecular subtypes of screen-detected vs symptomatic breast cancers accounted in part for the better outcome of screen-detected cancers, however, the effect of molecular subtype on the survival advantage conferred by screen detection was not assessed in this analysis.

The policy of offering mammographic screening has led to a reduction in breast cancer mortality of around 20\% (Vainio, 2002). The population mortality benefit occurs as a result of the much higher survival observed in screen-detected cancers. Around twothirds of this survival benefit can be accounted for by age and shift in the NPI. The residual survival advantage from screen detection, although small, currently remains unexplained. Despite obvious differences in the molecular characteristics of screen-detected $v s$ symptomatic tumours, our analysis indicates that these differences in tumour biology only account for a small proportion of the residual survival benefit. Measurement of tumour attributes is not 
perfect and there may be some residual variability in survival, which might be better explained by stage and other histological tumour characteristics if these were measured more precisely. In addition, there are prognostic factors that were unavailable to us, such as lymphovascular invasion. Adjustment for these might further explain some of the better survival of screen-detected cases. However, currently known biomarkers and tumour characteristics still remain limited in their ability to explain the heterogeneity of breast cancer fully. It is likely that a more complete understanding of the biological profile of breast tumours will be necessary to eliminate potential length bias and adjust for its impact on the improvement in survival seen with screen detection.

\section{ACKNOWLEDGEMENTS}

GCW and CC received research funding from the Cambridge NIHR Biomedical Research Centre. Gordon C Wishart has had full access to the data in this study and had final responsibility for the decision to submit for publication.

\section{REFERENCES}

Abd El-Rehim DM, Ball G, Pinder SE, Rakha E, Paish C, Robertson JF, Macmillan D, Blamey RW, Ellis IO (2005) High-throughput protein expression analysis using tissue microarray technology of a large wellcharacterised series identifies biologically distinct classes of breast cancer confirming recent cDNA expression analyses. Int J Cancer 116: $340-350$

Azzato EM, Greenberg D, Shah M, Blows F, Driver KE, Caporaso NE, Pharoah PD (2009) Prevalent cases in observational studies of cancer survival: do they bias hazard ratio estimates? Br J Cancer 100: 1806-1811

Callagy G, Cattaneo E, Daigo Y, Happerfield L, Bobrow LG, Pharoah PD, Caldas C (2003) Molecular classification of breast carcinomas using tissue microarrays. Diagn Mol Pathol 12: 27-34

Callagy GM, Pharoah PD, Pinder SE, Hsu FD, Nielsen TO, Ragaz J, Ellis IO, Huntsman D, Caldas C (2006) Bcl-2 is a prognostic marker in breast cancer independently of the Nottingham Prognostic Index. Clin Cancer Res 12: $2468-2475$

Callagy GM, Webber MJ, Pharoah PD, Caldas C (2008) Meta-analysis confirms BCL2 is an independent prognostic marker in breast cancer. BMC Cancer 8: 153

Carlson RW, Moench SJ, Hammond ME, Perez EA, Burstein HJ, Allred DC, Vogel CL, Goldstein LJ, Somlo G, Gradishar WJ, Hudis CA, Jahanzeb M, Stark A, Wolff AC, Press MF, Winer EP, Paik S, Ljung BM (2006) HER2 testing in breast cancer: NCCN Task Force report and recommendations. J Natl Compr Canc Netw 4(Suppl 3): S1 -22; quiz S23-24

Collett K, Stefansson IM, Eide J, Braaten A, Wang H, Eide GE, Thoresen SO, Foulkes WD, Akslen LA (2005) A basal epithelial phenotype is more frequent in interval breast cancers compared with screen detected tumors. Cancer Epidemiol Biomarkers Prev 14: 1108-1112

Crosier M, Scott D, Wilson RG, Griffiths CD, May FE, Westley BR (1999) Differences in Ki67 and c-erbB2 expression between screen-detected and true interval breast cancers. Clin Cancer Res 5: 2682-2688

Freedman LS, Graubard BI, Schatzkin A (1992) Statistical validation of intermediate endpoints for chronic diseases. Stat Med 11: 167-178

Gotzsche PC, Nielsen M (2006) Screening for breast cancer with mammography. Cochrane Database Syst Rev, CD 001877

Jacquemier J, Ginestier C, Rougemont J, Bardou VJ, Charafe-Jauffret E, Geneix J, Adelaide J, Koki A, Houvenaeghel G, Hassoun J, Maraninchi D, Viens P, Birnbaum D, Bertucci F (2005) Protein expression profiling identifies subclasses of breast cancer and predicts prognosis. Cancer Res 65: $767-779$

Joensuu H, Lehtimaki T, Holli K, Elomaa L, Turpeenniemi-Hujanen T, Kataja V, Anttila A, Lundin M, Isola J, Lundin J (2004) Risk for distant recurrence of breast cancer detected by mammography screening or other methods. JAMA 292: 1064-1073

Kononen J, Bubendorf L, Kallioniemi A, Barlund M, Schraml P, Leighton S, Torhorst J, Mihatsch MJ, Sauter G, Kallioniemi OP (1998) Tissue

\section{Authors contribution}

S-JD: concept, study design, interpretation of results, writing, editing; SWD: interpretation of results, statistical analysis, writing; FMB: TMA construction, clinical database construction and maintenance; KED: TMA construction, clinical database construction and maintenance; EP: scoring of immunohistochemistry and interpretation of results; JLQ: pathology review of cases, marking of slides for TMA construction; DCG: study design, data management and analysis, writing; PP: study design, statistical analysis, interpretation of results, writing, editing; CC: study design, interpretation of results, writing, editing; GCW: concept, study design, interpretation of results, writing, editing and submission.

\section{Conflict of interest}

The authors declare no conflict of interest.

Supplementary Information accompanies the paper on British Journal of Cancer website (http://www.nature.com/bjc) microarrays for high-throughput molecular profiling of tumor specimens. Nat Med 4: 844-847

Leake R, Barnes D, Pinder S, Ellis I, Anderson L, Anderson T, Adamson R, Rhodes T, Miller K, Walker R (2000) Immunohistochemical detection of steroid receptors in breast cancer: a working protocol. UK Receptor Group, UK NEQAS, The Scottish Breast Cancer Pathology Group, and The Receptor and Biomarker Study Group of the EORTC. J Clin Pathol 53: $634-635$

Lesueur F, Pharoah PD, Laing S, Ahmed S, Jordan C, Smith PL, Luben R, Wareham NJ, Easton DF, Dunning AM, Ponder BA (2005) Allelic association of the human homologue of the mouse modifier Ptprj with breast cancer. Hum Mol Genet 14: 2349-2356

Nielsen TO, Hsu FD, Jensen K, Cheang M, Karaca G, Hu Z, HernandezBoussard T, Livasy C, Cowan D, Dressler L, Akslen LA, Ragaz J, Gown AM, Gilks CB, van de Rijn M, Perou CM (2004) Immunohistochemical and clinical characterization of the basal-like subtype of invasive breast carcinoma. Clin Cancer Res 10: 5367-5374

Perou CM, Sorlie T, Eisen MB, van de Rijn M, Jeffrey SS, Rees CA, Pollack JR, Ross DT, Johnsen H, Akslen LA, Fluge O, Pergamenschikov A, Williams C, Zhu SX, Lonning PE, Borresen-Dale AL, Brown PO, Botstein D (2000) Molecular portraits of human breast tumours. Nature 406: $747-752$

Porter PL, El-Bastawissi AY, Mandelson MT, Lin MG, Khalid N, Watney EA, Cousens L, White D, Taplin S, White E (1999) Breast tumor characteristics as predictors of mammographic detection: comparison of interval- and screen-detected cancers. J Natl Cancer Inst 91: 2020-2028

Rakha EA, El-Sayed ME, Green AR, Lee AH, Robertson JF, Ellis IO (2007) Prognostic markers in triple-negative breast cancer. Cancer 109: 25-32

Rakha EA, Putti TC, Abd El-Rehim DM, Paish C, Green AR, Powe DG, Lee AH, Robertson JF, Ellis IO (2006) Morphological and immunophenotypic analysis of breast carcinomas with basal and myoepithelial differentiation. J Pathol 208: $495-506$

Shapiro S, Goldberg JD, Hutchison GB (1974) Lead time in breast cancer detection and implications for periodicity of screening. Am J Epidemiol 100: $357-366$

Shen Y, Yang Y, Inoue LY, Munsell MF, Miller AB, Berry DA (2005) Role of detection method in predicting breast cancer survival: analysis of randomized screening trials. J Natl Cancer Inst 97: 1195-1203

Sihto H, Lundin J, Lehtimaki T, Sarlomo-Rikala M, Butzow R, Holli K, Sailas L, Kataja V, Lundin M, Turpeenniemi-Hujanen T, Isola J, Heikkila P, Joensuu H (2008) Molecular subtypes of breast cancers detected in mammography screening and outside of screening. Clin Cancer Res 14: $4103-4110$

Sorlie T, Tibshirani R, Parker J, Hastie T, Marron JS, Nobel A, Deng S, Johnsen H, Pesich R, Geisler S, Demeter J, Perou CM, Lonning PE, Brown PO, Borresen-Dale AL, Botstein D (2003) Repeated observation of breast 
tumor subtypes in independent gene expression data sets. Proc Natl Acad Sci USA 100: $8418-8423$

Sundquist M, Thorstenson S, Brudin L, Nordenskjold B (1999) Applying the Nottingham Prognostic Index to a Swedish breast cancer population. South East Swedish Breast Cancer Study Group. Breast Cancer Res Treat 53: $1-8$

Vainio H (2002) IARC Handbooks of Cancer Prevention: Breast Cancer Screening. IARC Press: Lyon

Weaver DL, Rosenberg RD, Barlow WE, Ichikawa L, Carney PA, Kerlikowske K, Buist DS, Geller BM, Key CR, Maygarden SJ, Ballard-
Barbash R (2006) Pathologic findings from the Breast Cancer Surveillance Consortium: population-based outcomes in women undergoing biopsy after screening mammography. Cancer 106: $732-742$

Wishart GC, Greenberg DC, Britton PD, Chou P, Brown CH, Purushotham AD, Duffy SW (2008) Screen-detected vs symptomatic breast cancer: is improved survival due to stage migration alone? $\mathrm{Br} J$ Cancer 98: 1741 - 1744

Zahl PH, Strand BH, Maehlen J (2004) Incidence of breast cancer in Norway and Sweden during introduction of nationwide screening: prospective cohort study. BMJ 328: $921-924$ 